\title{
Review Article \\ Specifics and Challenges to Flexible Organic Light-Emitting Devices
}

\author{
Mariya Aleksandrova \\ Department of Microelectronics, Technical University of Sofia, "Kliment Ohridski" Boulevard 8, Block 1, \\ Room 1000B, 1000 Sofia, Bulgaria
}

Correspondence should be addressed to Mariya Aleksandrova; m_aleksandrova@tu-sofia.bg

Received 31 January 2016; Accepted 16 February 2016

Academic Editor: Peter Majewski

Copyright (C) 2016 Mariya Aleksandrova. This is an open access article distributed under the Creative Commons Attribution License, which permits unrestricted use, distribution, and reproduction in any medium, provided the original work is properly cited.

\begin{abstract}
Several recent developments in material science and deposition methods for flexible organic light-emitting devices (OLEDs) are surveyed. The commonly used plastic substrates are compared, according to their mechanical, optical, thermal, and chemical properties. Multilayer electrode structures, used as transparent electrodes, replacing conventional indium tin oxide (ITO) are presented and data about their conductivity, transparency, and bending ability are provided. Attention is paid to some of the most popular industrial processes for flexible OLEDs manufacturing, such as roll-to-roll printing, inkjet printing, and screen printing. Main specifics and challenges, related to the foils reliability, mechanical stability of the transparent electrodes, and deposition and patterning of organic emissive films, are discussed.
\end{abstract}

\section{Introduction}

The development of material science and technology has led to many advantages, related to the flexible display devices [1]. In comparison to the conventional rigid displays, the flexible ones are durable and cannot be broken under shock [2]. Due to the possibility for application of printing technology, the area of the device can be large. New applications can be promoted, such as e-papers, implementation of clothes with incorporated displays (especially for military purposes), and electronic posters and labels [3]. Recently, more preferable is organic light-emitting display (OLED) technology, compared to other types of displays, due to the following advantages: self-lightening; high brightness; greater variation of colors, due to dyes application for the emissive layers; low temperature and low-cost vacuum-free deposition methods (spray, inkjet); low power consumption, due to the low conductivity of the organic materials and lack of backlight panel (in contrast to LCD displays). Moreover, eventually flexing the panel of LCD will create forces that will cause the liquid crystals to flow, resulting in their irregular distribution in the display cell and visual distortions [4]. Despite the positive features of OLED technology, there are still some specifics and challenges, related to their flexibility, that should be overcome, before realization of reliable and long-term working commercial devices. Currently, the drawbacks of the flexible OLEDs can be divided into three general groups, discussed below in the paper: (1) problems, related to the thermal and chemical instability of the flexible substrates; (2) problems with the adhesion and mechanical stability of the films deposited on the plastic substrates (especially of the metal and metal oxide electrodes); (3) difficulties, related to the patterning of the deposited films, due to poor solvent resistance of the flexible foils and the large treated area that is required.

In this regard, the aim of the review is to provide brief, useful information about the above-mentioned specifics and challenges to the fabrication of flexible organic light-emitting devices. The paper will give readers an idea to which extent the problems described have been solved, what the level of commercialization of the flexible OLEDs is, and which are the main publications on the subject. 


\section{Typically Used Flexible Substrates and Their Thermal Stability}

For the need of lightweight and bendable organic lightemitting (and other electronic) devices, a variety of plastic substrates (foils), fulfilling the requirements for mechanical and optical properties, have been developed [5, 6]. Cellulose based substrates have been also studied and demonstrated [7], but they will be not considered in this review due to the lack of commercialization of such devices yet. Although most of the foils are characterized by high transparency and flexibility, their degradation temperature is relatively low $\left(100-150^{\circ} \mathrm{C}\right)$, compared to the rigid substrates. This requires low temperature deposition processes to be used for the functional films. Foils that exhibit high thermal stability, such as polyimide (PI), for example, are not transparent enough. The requirement for the transparency in the visible region is $>95 \%$. The transparent substrates, such as polycarbonate (PC), show modest solvent resistance. Another key issue in achieving high level of commercialization of flexible OLEDs is necessity of additional barrier and passivation films on plastic substrates for humidity and oxygen penetration protection. Although universal flexible substrate has not been found yet, the polymers polyethylene terephthalate (PET) and polyethylene naphthalate (PEN) are nowadays applied with success in the flexible electronics. This is due to their excellent mechanical and optical properties, as well as relatively good thermal stability and solvent resistance, as well as poor moisture and oxygen absorption. Table 1 summarizes the main properties of the plastic substrates used. Figure 1 shows the flexing capability of PEN substrate with fabricated pixels on its surface.

Plastic materials can be thermally stabilized [14], but then they lose partially the ability of bending; the possible radius of curvature increases and restricts the rolling of the device. Despite the advantages of low-cost plastic substrates, the main challenges are their thermal expansion and degradation, arising as a result of the fabrication processes required temperatures higher than $100^{\circ} \mathrm{C}$. For example, residual stress arises in the foils from the vacuum sputtering of ITO on PET [15]. It is necessary modification of the deposition modes during films growth, which may cause amorphous microstructure of the oxide films. However, the amorphous films are characterized by higher sheet resistance in comparison to the crystalline phase, resulting in high turn-on voltage of OLED.

Thermal deformations in the foils can occur also during continuous operation at extreme conditions, such as maximum brightness (resp., maximum current density). This effect results in $20 \%$ increasing of the sheet resistance of conductive film deposited on PEN substrate, for example. Moreover, it was demonstrated that at $\sim 115^{\circ} \mathrm{C}$ PET foil is deformed and bent to radius of curvature $\sim 1 \mathrm{~m}$ [16]. Regarding tensile and compressive stress at room temperature, PET and PEN have similar mechanical behavior; they are stable at multiple bending (>20 000) and no cracking has been observed. In terms of chemical stability, it is important resistance to cleaning solutions (ethanol and isopropanol containing), as well as to the solvent of the organic solutions (most often chloroform, toluene, and chlorobenzene). Modest resistance
TABLE 1: Main properties of the commercially available $100 \mu \mathrm{m}$ thick plastic substrates for flexible OLEDs application [8-12].

\begin{tabular}{lcccc}
\hline Properties & PET & PEN & PI & PC \\
\hline Flexibility (tensile strength, MPa) & 230 & 200 & 150 & 75 \\
Elasticity (Young modulus, GPa) & $2.8-3$ & $3-5$ & $2-3$ & 2.4 \\
Thermal conductivity, W/m·K & 0.20 & 0.15 & 0.25 & 0.22 \\
$\begin{array}{l}\text { Coefficient of thermal expansion, } \\
\mu \mathrm{m} /{ }^{\circ} \mathrm{C}\end{array}$ & 33 & 20 & 30 & 66 \\
$\begin{array}{l}\text { Transition temperature, }{ }^{\circ} \mathrm{C} \\
\text { Transparency in the visible }\end{array}$ & $90-100$ & 120 & 270 & 145 \\
region, \% & $>90$ & 88 & $65-70$ & 90 \\
Water absorption, $\%$ & 0.6 & 0.4 & 2.9 & 0.3 \\
Solvent resistance & Good & Good & Good & Poor \\
\hline
\end{tabular}
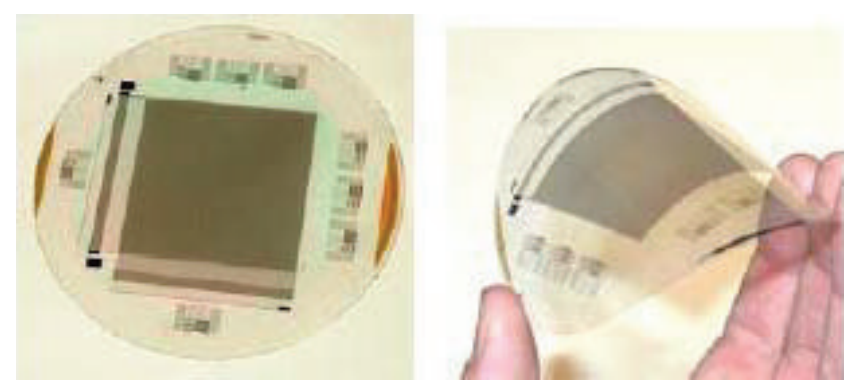

FIgURE 1: Pixel array fabricated on flexible PEN plastic substrate [13].

to acetone at longer treatment is typically observed for some glycol modifications of PET [17]. Wetting ability of the plastic surface is also essential property for organic solutions utilization, as the flexible substrates are mostly hydrophobic. Variety of pretreatment methods has been developed for application before wet deposition process for surface tension decreasing and improvement of the wetting conditions. Some methods, widely spread in the industry, are low pressure cold gas plasma (microwave/RF), electrical (corona discharge), and flame plasma, UV ozone treatment [18-20]. The choice of certain method depends on the substrate material; for example, the heat generated by the flame plasma can damage low melting point substrates, such as PET $\left(\sim 100^{\circ} \mathrm{C}\right)$, but it is suitable for polystyrene $\left(\mathrm{PS}, \sim 200^{\circ} \mathrm{C}\right.$ ) or polyimide (PI, $\sim 270^{\circ} \mathrm{C}$ ) [8].

\section{Mechanical Stability of OLED Structures at Rolling and Bending}

Among the serious problems of OLED technology is lack of highly flexible transparent electrodes. Indium tin oxide (ITO), which is the conventional material for this purpose in the glass based OLEDs, is known to be poor in terms of mechanical flexibility [21]. From the other side, when highly flexible transparent electrodes are developed, one more factor should be considered, achieving good balance between transparency and sheet resistance, while fulfilling the compatibility with the OLED device structure and fabrication processes. 


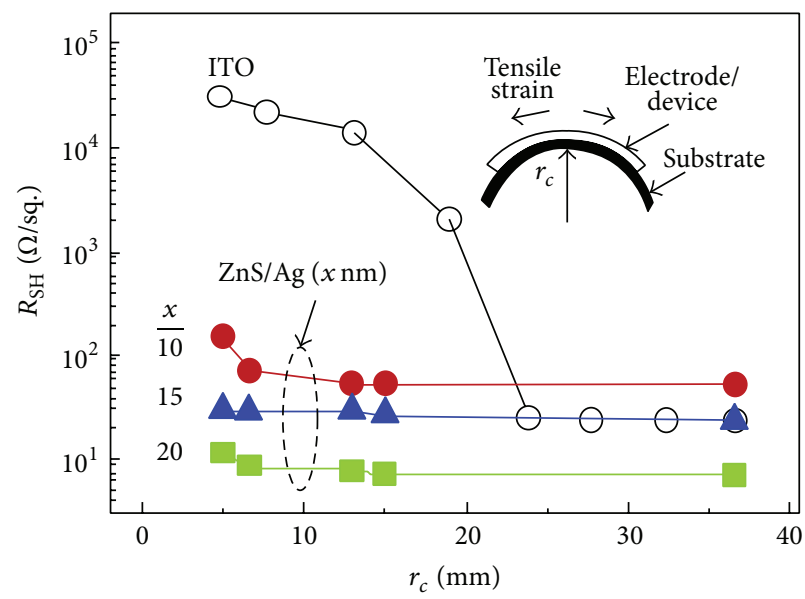

(a)

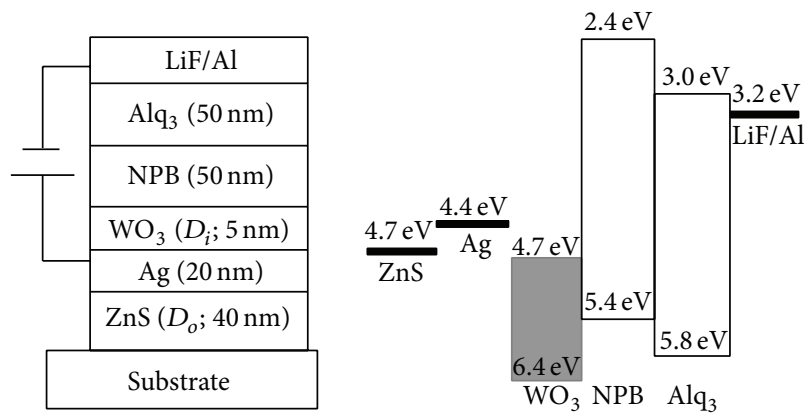

(b)

Figure 2: (a) Sheet resistance $\left(R_{\mathrm{SH}}\right)$ of $\mathrm{ZnS} / \mathrm{Ag} / \mathrm{WO}_{3}$ electrode films on PET, as a function of the radius of curvature $\left(r_{c}\right)$ after 50 times' bending; (b) band diagram of $\mathrm{Alq}_{3}$ based OLED using such $\mathrm{ZnS} / \mathrm{Ag} / \mathrm{WO}_{3}$ anode [30].

Indicator about high or low mechanical stability of coating is the value of intrinsic stress in thin films, caused by curvature [22]. However, this calculation is rather complex (there is a stress gradient with the radius of curvature) and many errors exist, due to nonlinear effects, including samples shapes and areas [23]. For this reason, the evaluation criteria for flexibility of conductive films, widely accepted in the practice, are degree of sheet resistance change and number of microcracks per unit area at static or dynamic bend mode. For most of the studied multilayer system the cracks are mainly propagated in direction $90^{\circ}$ tilted to the mechanical loading supplying direction, independent of the inner or outer bending. Normally, techniques such as scanning electron microscopy (SEM), high resolution transmission electron microscopy (HRTEM), and/or atom force microscopy (AFM) are used for visual inspection of the surface. For detection of the sheet resistance change, accurate measurement technique is four-point probe (or Van der Pauw method) [24].

One of the most studied potential alternatives to ITO on flexible substrate is the ITO-free transparent electrode, consisting of metal oxide/metal/metal oxide multilayer system. Typically, ITO is replaced by other nonconductive transparent oxides. Ductile metal (most often silver), contributing to the conductivity, is sandwiched between them. The metal film is very thin (less than $20 \mathrm{~nm}$ ) to avoid decreasing of the transmittance in the visible region. Reports exist about the electrooptical and mechanical characteristics of $\mathrm{Al}_{2} \mathrm{O}_{3} / \mathrm{Ag} / \mathrm{Al}_{2} \mathrm{O}_{3}$ [25], $\mathrm{ZnO} / \mathrm{Ag} / \mathrm{ZnO}$ [26], ultrathin $\mathrm{Ag}$ film, inserted between Mn-doped tin oxide films [27], $\mathrm{MoO}_{3} / \mathrm{Ag} / \mathrm{MoO}_{3}$ [28], $\mathrm{TiO}_{2} / \mathrm{Ag} / \mathrm{TiO}_{2}$ [29], and so forth. The results presented are still contradictory, as some authors emphasize the high optical transparency of almost $90 \%$ for the visible spectrum, without mentioning the film resistance variation at stress. Other authors put stress on the small radius of curvature of $6 \mathrm{~mm}$ and great number of repeating bend cycles of 5000 that the structure can stand with negligible change of the sheet resistance (in the range of $13-22 \Omega$ /square). However, the average optical transparency obtained is far below $85 \%$. In the cases when optimum compromise between conductivity (4.98 $\Omega$ /square), transparency (95\%), and mechanical stability is achieved (few percent variation of the sheet resistance), the mechanical test conditions are not intensive. Usually, the frequency of the bending cycles is $1 \mathrm{~Hz}$ and radius of curvature is $10 \mathrm{~mm}$. Data about the turn-on voltage, current, luminance, efficiency, and other working characteristics of the complete optoelectronic structure are provided, but the long-term reliability is rarely commented on.

Promising results are available for application of sulfite based electrode, such as $\mathrm{ZnS} / \mathrm{Ag} / \mathrm{WO}_{3}$ [30]. The relative change of the sheet resistance as a function of the radius of curvature, causing tensile stress in the layers, is almost constant even at radius lower than $5 \mathrm{~mm}$ (Figure 2(a)). In contrast, the mechanical flexibility over conventional ITO electrodes on PET flexible substrate is rather poor; sheet resistance change is almost $49 \%$ at radius of $10 \mathrm{~mm}$ and 50 cyclic bends. In addition, the contact between $\mathrm{ZnS} / \mathrm{Ag} / \mathrm{WO}_{3}$ electrode and the organic films $\mathrm{N}, \mathrm{N}^{\prime}-\mathrm{Di}\left(1\right.$-naphthyl)-N, $\mathrm{N}^{\prime}$ diphenyl-(1,1'-biphenyl)-4, $4^{\prime}$-diamine (NPB) leads to decrease in the energy barrier for holes injection, resulting in better current efficiency (Figure 2(b)).

Promising candidate for flexible OLED applications is graphene. It may serve as a transparent conductive electrode, due to the high optical transmittance and conductivity, high mechanical strength, flexibility, and chemical stability [31]. Interesting approach is growth of large-area graphene on $\mathrm{Cu}$ foil by using the low carbon solubility in $\mathrm{Cu}^{23}$ and it used polymethyl-methacrylate (PMMA) to aid the transfer of graphene to PET substrate without defects [32]. When the film was bent, its resistance in lateral and transversal directions remained almost independent of the bend cycles for radius $3 \mathrm{~mm}$ (tensile strain $\sim 5 \%$ ) (Figure $3(\mathrm{a})$ ). When the radius was decreased to $1 \mathrm{~mm}$ (tensile strain $~ 15 \%$ ), then the resistance in transversal direction increased by a factor of 2 .

Attention deserves proposition of new approach to achieve low sheet resistance of CVD monolayer grapheme on large scale, by using nonvolatile ferroelectric polymer. In 


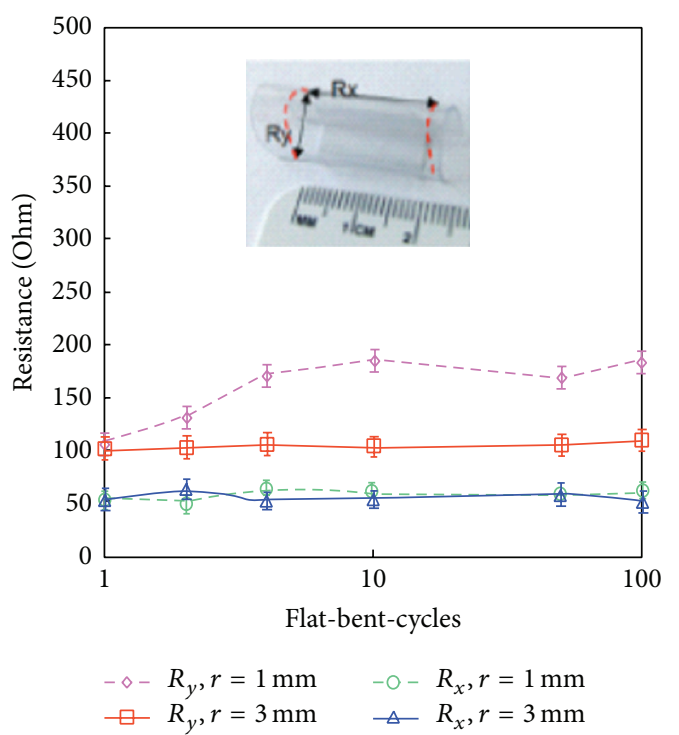

(a)

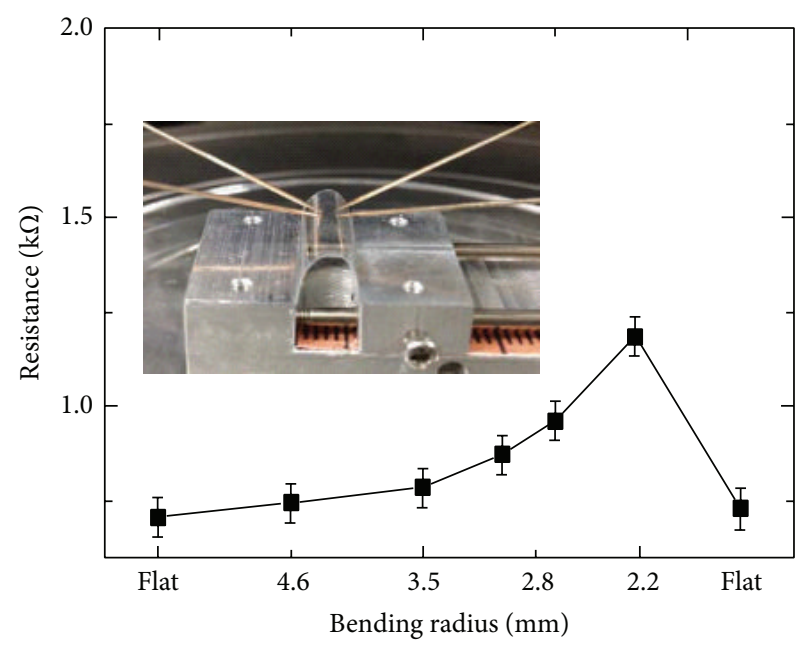

(b)

FIGURE 3: (a) Resistance of graphene/PMMA films with different bending radii and flat-fold cycles [32]; (b) mechanical foldability measurement of GFeTCs on PET $(200 \mu \mathrm{m})$ substrate [33]. (a) is reprinted with permission from [32]. (b) is reprinted with permission from [33].

this composite structure the graphene sheets are doped by poly(vinylidene fluoride-co-trifluoroethylene) ( $\mathrm{P}(\mathrm{VDF}-$ TrFE)), yielding a low sheet resistance of $120 \Omega$ /square and more than $95 \%$ transmittance in the visible range owing to the highly transparent nature of the ferroelectric polymer [33]. Figure 3(b) shows the film folding ability on PET substrate by measuring its resistance as a function of the bending radius. The resistance showed a small increase at bending radius of $3 \mathrm{~mm}$. The initial value of the resistance is repeatedly restored even after bending the sample to radius of $1 \mathrm{~mm}$ (this is equivalent to tensile strain of $\sim 11 \%$ ).

The superior mechanical properties of all structures, compared to ITO-based devices, were ascribed to the intermediate metal films with good ductility. However, these structures are complex (at least three layers) and most often require vacuum deposition process, making them expensive and restricting their size. Moreover, the metal film thickness (usually between 10 and $18 \mathrm{~nm}$ ) should be precisely controlled, as the elastic properties (Young's modulus) strongly vary with the thickness in the nanometric range.

Recently, the idea that flexible OLEDs may work without inorganic films has been developed and the brittle components have been replaced by organic materials. Various transparent electrodes with an excellent flexibility, such as conducting polymers [34], graphene/multiwalled carbon nanotube [35], and single carbon nanotube (CNT) films [36], have been studied in an effort to realize reliable and highly flexible OLED displays. However, the sheet resistance of those electrodes is still limited, due to their nature (i.e., hopping mechanism of charge carriers' conduction). Although currently films with sheet resistance lower than $100 \Omega$ /square and optical transmission of $\sim 85 \%$ have been produced $[37,38]$, these parameters should be further improved. Many of the structures exhibit relative change of the sheet resistance in the range between $8 \%$ and $16 \%$ at bending radius between 9 and $6 \mathrm{~mm}$ and repeating bend cycles greater than 300. This is superior in comparison to the metal oxide/metal/metal oxide electrodes. Additionally, the fabrication process is simpler and cheaper (spray coating, spin coating). Similar approach, with insertion of intermediate metal film having suitable refractive index between two polymeric films, has been studied for improvement of the electrical conductivity [39]. It was found that electrodes poly(N-vinylcarbazole) (PVK)/Ag/PVK and PVK/Ag/PEDOT:PSS show desired electrooptical properties; the sheet resistance can be decreased down to $10 \Omega$ /square, and the maximum transmittance can be higher than $85 \%$. Variation of sheet resistance less than $2 \%$ after 500 bends has been reported, which is in agreement with the current requirements of the consumer flexible optoelectronics.

\section{Deposition and Patterning of Organic Emissive and Charge Carriers Transporting Films on Flexible Substrates}

Although no serious problems have been identified with the mechanical stability of the color organic films in flexible OLEDs, there are still some limitations related to their patterning for pixels formation. Conventional processes for coatings patterning are photolithography and lift-off. However, it is known that the flexible substrates have low solvents resistance, which excludes application of etching and stripping solutions (or in general excludes subtractive methods). This imposes development of novel additive deposition processes, giving directly imprints (or stamps) and in the same time fulfilling the requirements for low-cost high quality coating of large areas $[5,40]$. In the recent years, very popular manufacturing process has become roll-to-roll (R2R) printing of 


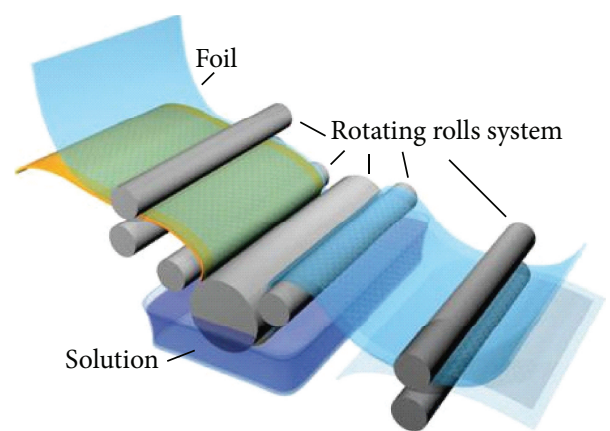

Figure 4: Roll-to-roll deposition of organic films on foil [42]. Adapted by permission from Macmillan Publishers Ltd. [Nature Nanotechnology] [42].

polymer films on PET solutions (Figure 4). The main idea is deposition of organic inks on defined location forming pattern in single step directly on rollable substrates $[8,41]$. Main advantage of the printing methods, irrespective of whether they are contact (screen printing, e.g.) or noncontact (ink jet printing), is possibility for direct patterning during the deposition itself. In this way, safety conditions for the flexible substrates are provided and treatments typical for the photolithography solvents are avoided.

At the screen printing, the desired pattern is preliminarily defined by the openings in screen made by photolithography. Density of the openings (their number per unit area) determines, so-called mesh, or defines the size of the organic particles that can pass through the openings when a squeegee moves over the ink. To provide the necessary thixotropy of the inks, despite their viscosity, additional binder polymers should be mixed to the functional organic compounds. The thickness of the organic films produced varies in broad range, between $100 \mathrm{~nm}$ and $50 \mu \mathrm{m}$ [43-45]. It was found that, for thick screen printed film (in the range of micrometers), dissipation of the heat generated during device operation is better. This is due to the higher volume of the functional organic material. Figure 5(a) shows luminous efficiency of OLED with screen printed layer of low-molecular weight compound and polymeric binder at different currents and after 400 repeating bends. It is average $3.5 \mathrm{~cd} / \mathrm{A}$ and the power consumption in this current range is low, between $35.7 \mathrm{~mW}$ and $73.4 \mathrm{~mW}$. This is great advantage for portable devices [46]. Figure 5(b) shows microscopic images of screen printed organic electroluminescent layer with thickness of $2 \mu \mathrm{m}$ at static bending. The morphology of the layers suggests that there is continuous distribution of organic particles without microcracks propagation, due to the mechanical stability of the thick films, as well as due to the presence of binder substance. At bending radius of $5 \mathrm{~mm}$, there is only redistribution of the larger clusters on the surface, which have remained unhomogenized during ink preparation. On the contrary, at the thin screen printed inks heat dissipation is not sufficient. Heat is accumulated inside the structure and causes melting of the flexible substrate at currents higher than few $\mathrm{mA} / \mathrm{cm}^{2}$ (resp., at higher brightness).

Still the main challenge, related to this process, is the low resolution of the stamp, as the mesh dimension cannot be infinitively low. The stamp consists of relatively large organic particles with size equal to the mesh openings. It is necessary additional thermal treatment of the screen printed layers for ink reflowing, fully removing the ink solvent, and homogenization and stabilization of the imprint. Thermal treatment should be conducted at temperatures lower than the deformation temperature of the flexible foil, which however restricts the choice of inks and binders. Residual solvent or unreflowed clusters increase the surface roughness of the layer, which results in higher contact resistance and can be reason for luminous efficiency lower than $5 \mathrm{~cd} / \mathrm{A}$.

For higher throughput principle of screen printing can be realized by rotary printer with moving substrate between cylindrical mask and impression cylinder, but this method is still under test for organic materials on foil.

Ink jet printing is technique that uses nozzle head to spread low viscosity inks. The droplets ejected can be very fine due to the ultrasonic generation of the aerosol flow, similarly to some electrospray systems [8]. Films in the range of few nanometers can be easily tailored, as picoliter level volume control is achievable for the printer head [48]. However, because the solubility of the materials is controlled by the solvent type and volatility, various film defects upon drying may occur, such as cracking, intrinsic stress, and peeling off. Velocity of residual solvent evaporation before the next printing step, requested to densify the film, restricts the printing rate. Another challenge with this technique is achieving uniform distribution of the droplet flow over the flexible substrates surface, which is often hydrophobic by nature. This requires preliminary treatments of the plastic surfaces, resulting in improved wetting from the printed patterns, such as plasma, solvent, or ultraviolet exposure $[38,49,50]$.

Gravure printing is another popular large-area technique for deposition of hole transporting and emissive and electron transporting layers in OLEDs on plastic substrate. It is higherspeed in comparison to the above considered roll-to-roll printing processes [51]. The printing roll, picking ink from reservoir, has engraved cells for surface patterning. The shape of cell and density of the imprints can vary. Special blade removes the excess of ink to guarantee uniformity of ink distribution in each cell. Main challenge with this method remains the low emission efficiency of the fabricated OLED, although some studies show promising and improving results. For example, Chung et al. have reported about high performance PLED with maximum quantum efficiency of $8.8 \mathrm{~lm} / \mathrm{W}$ and maximum luminance of $66,000 \mathrm{~cd} / \mathrm{m}^{2}$ [52].

Techniques like flexography printing [53], microcontact printing, and nanoimprinting [54] are expected to be optimized and to receive more popularity in future, but now many obstacles prevent their industrial applications. Some of them are low defects control, contaminations, deformations, and peeling of the stamps.

\section{Conclusion}

Flexible OLEDs will be the ultimate choice in the near future in the display industry, because of their advantages including portability and large-size and low-cost production. However, there are many challenges that should be still overcome. 


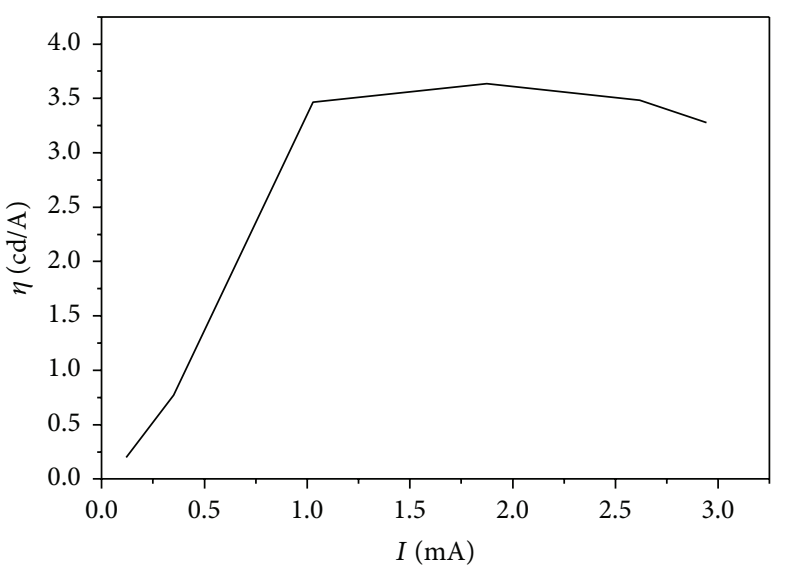

(a)

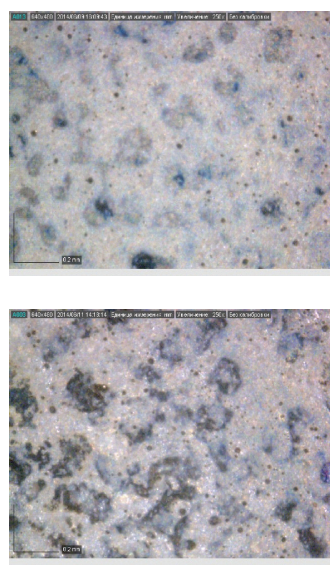

(b)

FIGURE 5: (a) Luminous efficiency of OLED with screen printed layer of low-molecular weight compound and polymer binder after 400 bends [46]. (b) Microscopic images of screen printed thick organic electroluminescent layer before bending (up) and after bending at radius of $5 \mathrm{~mm}$ (down) [47].

The use of plastic substrates for the needs of OLED fabrication offers numerous advantages over the glass substrates, including light weight, thinness, and conformability. Reliability and lifetime of the flexible devices, however, are still strongly dependent on the plastic materials' thermal expansion and moisture absorption.

The study on the mechanical properties, the cracking behavior, and technology dependable electrooptical characteristics of electrode coatings plays a key role in their design and applications. These properties are strongly dependent on deposition methods, doping processes, and films' microstructure.

Variety of deposition methods and their modifications exist for fabrication of organic films on flexible substrates. This review has no claim to consider all of them, but only those widely applied in the practice were considered. Although various deposition mechanisms are demonstrated for lab made flexible OLED devices, most of them are not suitable for larger production lines, due to different limitations, such as speed, defects in the coatings, and resolution. For large scale production roll-to-roll line is required for overcoming the problem with the speed. In any case, the future target of this manufacturing branch should be replacing of the solvents that are used for processing of conjugated polymers with less harmful substances. The trend will be possibly dry printing development, which requires progress of dry transferable materials.

\section{Competing Interests}

The author declares that there are no competing interests regarding the publication of this paper.

\section{References}

[1] M.-C. Choi, Y. Kim, and C.-S. Ha, "Polymers for flexible displays: from material selection to device applications," Progress in Polymer Science, vol. 33, no. 6, pp. 581-630, 2008.
[2] W. Bock, Advances in Flexible Electronics Displays, Pira International, 2005.

[3] J. W. Park, D. C. Shin, and S. H. Park, "Large-area OLED lightings and their applications," Semiconductor Science and Technology, vol. 26, no. 3, Article ID 034002, 2011.

[4] K. J. Allen, "Reel to real: prospects for flexible displays," Proceedings of the IEEE, vol. 93, no. 8, pp. 1394-1399, 2005.

[5] W. S. Wong and A. Salleo, Flexible Electronics: Materials and Applications, Springer Science \& Business Media, Berlin, Germany, 2009.

[6] P. E. Burrows, G. L. Graff, M. E. Gross et al., "Ultra barrier flexible substrates for flat panel displays," Displays, vol. 22, no. 2, pp. 65-69, 2001.

[7] S. Ummartyotin, J. Juntaro, M. Sain, and H. Manuspiya, "Development of transparent bacterial cellulose nanocomposite film as substrate for flexible organic light emitting diode (OLED) display," Industrial Crops and Products, vol. 35, no. 1, pp. 92-97, 2012.

[8] S. Khan, L. Lorenzelli, and R. S. Dahiya, "Technologies for printing sensors and electronics over large flexible substrates: a review," IEEE Sensors Journal, vol. 15, no. 6, pp. 3164-3185, 2015.

[9] J. G. Speight and N. A. Lange, Lange's Handbook of Chemistry, McGraw-Hill Professional, Maidenhead, UK, 16th edition, 2005.

[10] W. Martienssen and H. Warlimont, "Polymers," in Springer Handbook of Condensed Matter and Materials Data, chapter 3.3, pp. 477-522, Springer, 2005.

[11] A. K. van der Vegt and L. E. Govaert, Polymeren, van Keten tot Kunstof, Delft Academic Press, 2003.

[12] January 2016, http://www.teijindupontfilms.jp/english/product/ hi_film.html.

[13] K. R. Sarma, J. Roush, J. Schmidt, C. Chanley, and S. Dodd, "Flexible active matrix organic light emitting diode (AM OLED) displays," in Proceedings of the 9th Asian Symposium on Information Display (ASID '06), pp. 337-342, New Delhi, India, October 2006.

[14] W. A. MacDonald, M. K. Looney, D. Mackerron et al., "Latest advances in substrates for flexible electronics," Journal of the Society for Information Display, vol. 15, no. 12, pp. 1075-1083, 2007. 
[15] Y. Leterrier, L. Médico, F. Demarco et al., "Mechanical integrity of transparent conductive oxide films for flexible polymer-based displays," Thin Solid Films, vol. 460, no. 1-2, pp. 156-166, 2004.

[16] V. Zardetto, T. M. Brown, A. Reale, and A. Di Carlo, "Substrates for flexible electronics: a practical investigation on the electrical, film flexibility, optical, temperature, and solvent resistance properties," Journal of Polymer Science, Part B: Polymer Physics, vol. 49, no. 9, pp. 638-648, 2011.

[17] M. Aleksandrova, G. Kolev, I. Cholakova, G. Dobrikov, and G. Bodurov, "Photolithography versus lift off process for patterning of sputtered indium tin oxide for flexible displays," International Journal of Thin Films Science and Technology, vol. 2, no. 2, pp. 67-75, 2013

[18] S. R. Sabreen, Cold Gas Plasma Surface Modification-Optimize Plastics Bonding Adhesion, Technology Feature, 2010.

[19] M. Strobel, M. J. Walzak, J. M. Hill, A. Lin, E. Karbashewski, and C. S. Lyons, "Comparison of gas-phase methods of modifying polymer surfaces," Journal of Adhesion Science and Technology, vol. 9, no. 3, pp. 365-383, 1995.

[20] N. S. McIntyre and M. J. Walzak, "New UV/ozone treatment improves adhesiveness of polymer surfaces," Modern Plastics, pp. 79-84, 1995, http://infohouse.p2ric.org/ref/29/28881.pdf.

[21] Y. Leterrier, C. Fischer, L. Médico et al., "Mechanical properties of transparent functional thin films for flexible displays," Society of Vacuum Coaters, vol. 505, pp. 856-7188, 2003.

[22] X.-S. Wang, H.-P. Tang, X.-D. Li, and X. Hua, "Investigations on the mechanical properties of conducting polymer coatingsubstrate structures and their influencing factors," International Journal of Molecular Sciences, vol. 10, no. 12, pp. 5257-5284, 2009.

[23] A. Mézin, "Coating internal stress measurement through the curvature method: a geometry-based criterion delimiting the relevance of Stoney's formula," Surface and Coatings Technology, vol. 200, no. 18-19, pp. 5259-5267, 2006.

[24] SEMI, "Standard test method for sheet resistance uniformity evaluation by in-line four-point probe with the dual-configuration procedure," SEMI MF1529-1110, American Society for Testing and Materials, 1997, Reprinted from the Annual Book of ASTM Standards, Designation: F.

[25] J.-A. Jeong and H.-K. Kim, " $\mathrm{Al}_{2} \mathrm{O}_{3} / \mathrm{Ag} / \mathrm{Al}_{2} \mathrm{O}_{3}$ multilayer thin film passivation prepared by plasma damage-free linear facing target sputtering for organic light emitting diodes," Thin Solid Films, vol. 547, pp. 63-67, 2013.

[26] J. H. Kim, J. H. Lee, S.-W. Kim, Y.-Z. Yoo, and T.-Y. Seong, "Highly flexible $\mathrm{ZnO} / \mathrm{Ag} / \mathrm{ZnO}$ conducting electrode for organic photonic devices," Ceramics International, vol. 41, no. 5, pp. 7146-7150, 2015.

[27] C.-H. Lee, R. Pandey, B.-Y. Wang, W.-K. Choi, D.-K. Choi, and Y.-J. Oh, "Nano-sized indium-free MTO/Ag/MTO transparent conducting electrode prepared by RF sputtering at room temperature for organic photovoltaic cells," Solar Energy Materials and Solar Cells, vol. 132, pp. 80-85, 2015.

[28] T. Abachi, L. Cattin, G. Louarn et al., "Highly flexible, conductive and transparent $\mathrm{MoO}_{3} / \mathrm{Ag} / \mathrm{MoO}_{3}$ multilayer electrode for organic photovoltaic cells," Thin Solid Films, vol. 545, pp. 438444, 2013.

[29] J. H. Kim, D.-H. Kim, and T.-Y. Seong, "Realization of highly transparent and low resistance $\mathrm{TiO}_{2} / \mathrm{Ag} / \mathrm{TiO}$ conducting electrode for optoelectronic devices," Ceramics International, vol. 41, no. 2, pp. 3064-3068, 2015.
[30] H. Cho, C. Yun, J.-W. Park, and S. Yoo, "Highly flexible organic light-emitting diodes based on $\mathrm{ZnS} / \mathrm{Ag} / \mathrm{WO}_{3}$ multilayer transparent electrodes," Organic Electronics, vol. 10, no. 6, pp. 11631169, 2009.

[31] K. S. Kim, Y. Zhao, H. Jang et al., "Large-scale pattern growth of graphene films for stretchable transparent electrodes," Nature, vol. 457, no. 7230, pp. 706-710, 2009.

[32] X. Li, Y. Zhu, W. Cai et al., "Transfer of large-area graphene films for high-performance transparent conductive electrodes," Nano Letters, vol. 9, no. 12, pp. 4359-4363, 2009.

[33] G.-X. Ni, Y. Zheng, S. Bae et al., "Graphene-ferroelectric hybrid structure for flexible transparent electrodes," ACS Nano, vol. 6, no. 5, pp. 3935-3942, 2012.

[34] B.-J. Kim, S.-H. Han, and J.-S. Park, "Properties of CNTs coated by PEDOT:PSS films via spin-coating and electrophoretic deposition methods for flexible transparent electrodes," Surface and Coatings Technology, vol. 271, pp. 22-26, 2015.

[35] S. Yadav, V. Kumar, S. Arora, S. Singh, D. Bhatnagar, and I. Kaur, "Fabrication of ultrathin, free-standing, transparent and conductive graphene/multiwalled carbon nanotube film with superior optoelectronic properties," Thin Solid Films, vol. 595, pp. 193-199, 2015.

[36] J. Sun and R. Wang, "Carbon nanotube transparent electrode," in Syntheses and Applications of Carbon Nanotubes and Their Composites, S. Suzuki, Ed., chapter 14, pp. 313-335, InTech, Rijeka, Croatia, 2013.

[37] P. J. Glatkowski, “Transparent electrodes \& circuits from carbon nanotubes," in Proceedings of the USDC Flexible Displays Microelectron, Phoenix, Ariz, USA, 2005.

[38] M. Aleksandrova, N. Kurtev, V. Videkov, S. Tzanova, and S. Schintke, "Material alternative to ITO for transparent conductive electrode in flexible display and photovoltaic devices," Microelectronic Engineering, vol. 145, article 9805, pp. 112-116, 2015.

[39] X. Guo, X. Liu, F. Lin, H. Li, Y. Fan, and N. Zhang, "Highly conductive transparent organic electrodes with multilayer structures for rigid and flexible optoelectronics," Scientific Reports, vol. 5, Article ID 10569, 2015.

[40] Y. Aleeva and B. Pignataro, "Recent advances in upscalable wet methods and ink formulations for printed electronics," Journal of Materials Chemistry C, vol. 2, no. 32, pp. 6436-6453, 2014.

[41] J. Jensen, H. F. Dam, J. R. Reynolds, A. L. Dyer, and F. C. Krebs, "Manufacture and demonstration of organic photovoltaicpowered electrochromic displays using roll coating methods and printable electrolytes," Journal of Polymer Science, Part B: Polymer Physics, vol. 50, no. 8, pp. 536-545, 2012.

[42] Y. P. Chen and Q. Yu, "Nanomaterials: graphene rolls off the press," Nature Nanotechnology, vol. 5, no. 8, pp. 559-560, 2010.

[43] D.-H. Lee, J. S. Choi, H. Chae, C.-H. Chung, and S. M. Cho, "Screen-printed white OLED based on polystyrene as a host polymer," Current Applied Physics, vol. 9, no. 1, pp. 161-164, 2009.

[44] D.-H. Lee, J. S. Choi, H. Chae, C.-H. Chung, and S. M. Cho, "Highly efficient phosphorescent polymer OLEDs fabricated by screen printing," Displays, vol. 29, no. 5, pp. 436-439, 2008.

[45] D.-H. Lee, J. Choi, H. Chae, C.-H. Chung, and S. M. Cho, "Single-layer organic-light-emitting devices fabricated by screen printing method," Korean Journal of Chemical Engineering, vol. 25, no. 1, pp. 176-180, 2008.

[46] M. Aleksandrova and I. Nestorova, "Fabrication of flexible hybrid low molecular weight compound/polymer light emitting device by screen printing," Electrotechnica and Electronica, vol. 3/4, pp. 2-6, 2014. 
[47] M. Aleksandrova, S. Andreev, I. Ruskova, and G. Dobrikov, "Flexible thick film electroluminescent devices: influence of the mechanical stress on layers behavior," Annual Journal of Electronics, vol. 8, pp. 43-46, 2014.

[48] T. Sekitani, Y. Noguchi, U. Zschieschang, H. Klauk, and T. Someya, "Organic transistors manufactured using inkjet technology with subfemtoliter accuracy," Proceedings of the National Academy of Sciences of the United States of America, vol. 105, no. 13, pp. 4976-4980, 2008.

[49] F. Ely, C. O. Avellaneda, P. Paredez et al., "Patterning quality control of inkjet printed PEDOT:PSS films by wetting properties," Synthetic Metals, vol. 161, no. 19-20, pp. 2129-2134, 2011.

[50] A. Keawprajak, W. Koetniyom, P. Piyakulawat, K. Jiramitmongkon, S. Pratontep, and U. Asawapirom, "Effects of tetramethylene sulfone solvent additives on conductivity of PEDOT:PSS film and performance of polymer photovoltaic cells," Organic Electronics, vol. 14, no. 1, pp. 402-410, 2013.

[51] D. J. Gaspar and E. Polikarpov, OLED Fundamentals: Materials, Devices, and Processing of Organic Light-Emitting Diodes, CRC Press, 2015.

[52] D.-Y. Chung, J. Huang, D. D. C. Bradley, and A. J. Campbell, "High performance, flexible polymer light-emitting diodes (PLEDs) with gravure contact printed hole injection and light emitting layers," Organic Electronics: Physics, Materials, Applications, vol. 11, no. 6, pp. 1088-1095, 2010.

[53] D. Deganello, J. A. Cherry, D. T. Gethin, and T. C. Claypole, "Patterning of micro-scale conductive networks using reel-toreel flexographic printing," Thin Solid Films, vol. 518, no. 21, pp. 6113-6116, 2010.

[54] E. Menard, M. A. Meitl, Y. Sun et al., "Micro- and nanopatterning techniques for organic electronic and optoelectronic systems," Chemical Reviews, vol. 107, no. 4, pp. 1117-1160, 2007. 

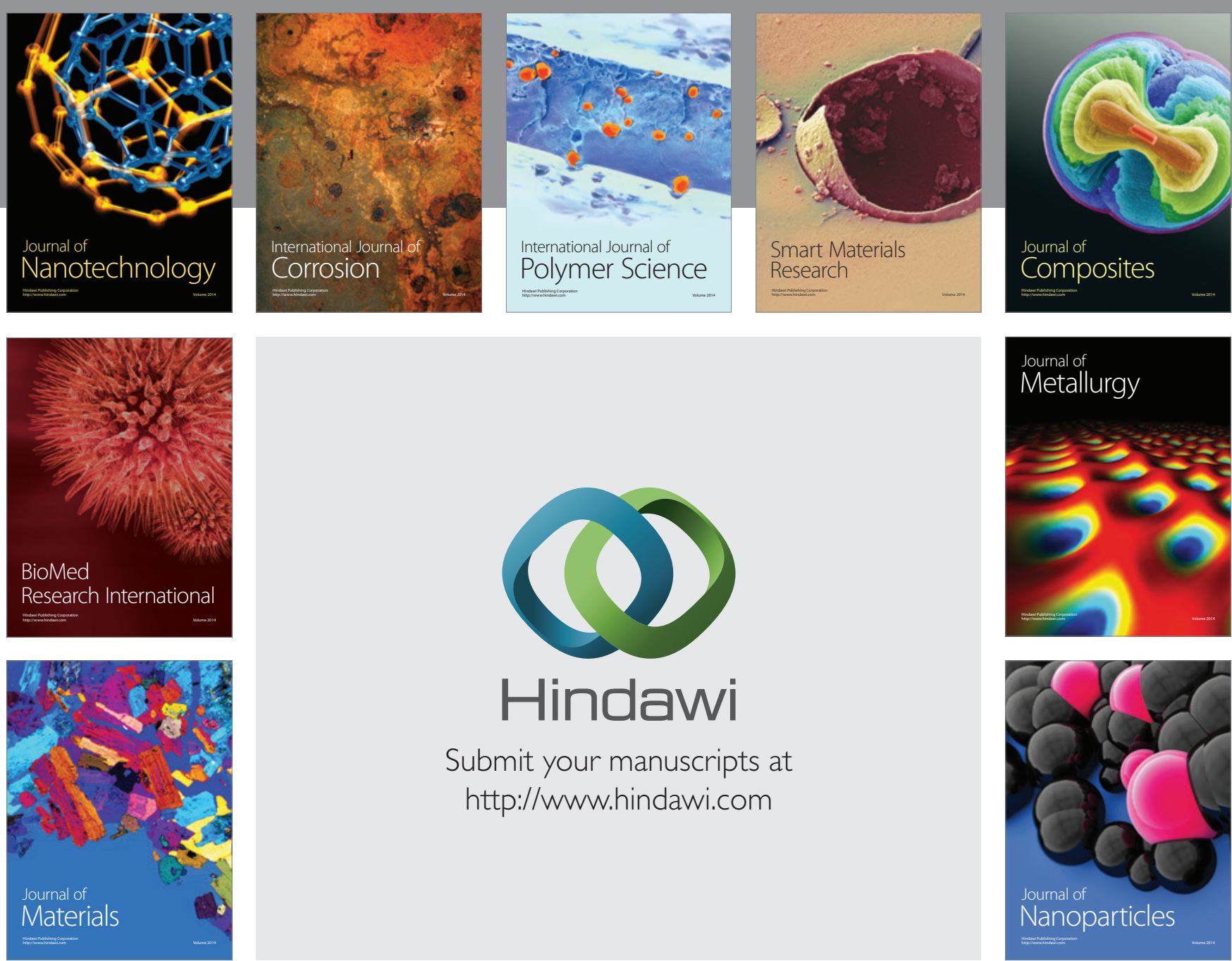

\section{Hindawi}

Submit your manuscripts at

http://www.hindawi.com

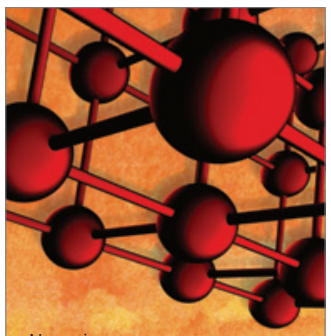

Materials Science and Engineering
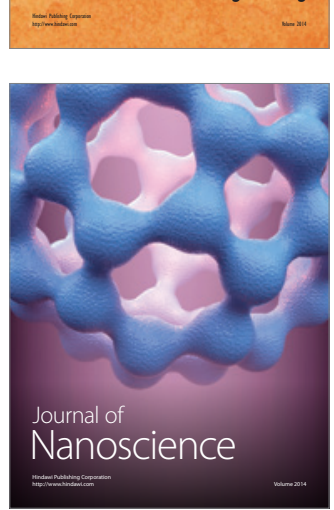
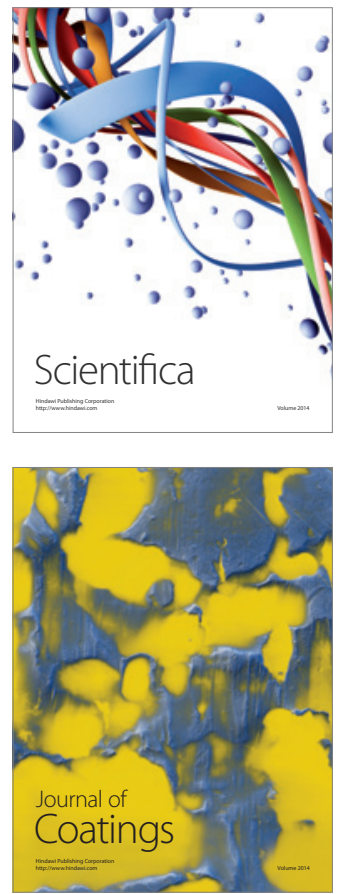
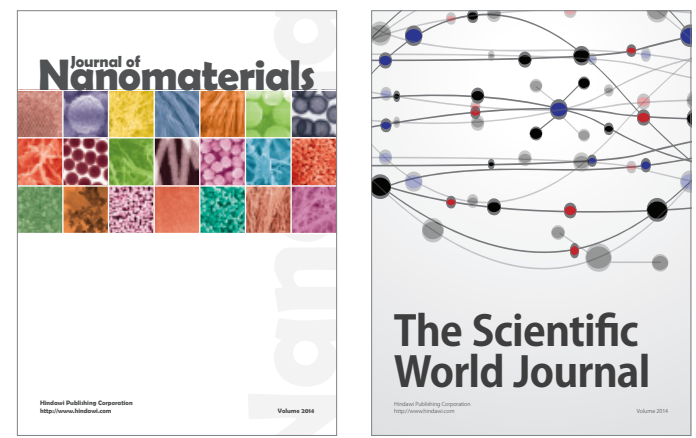

The Scientific World Journal
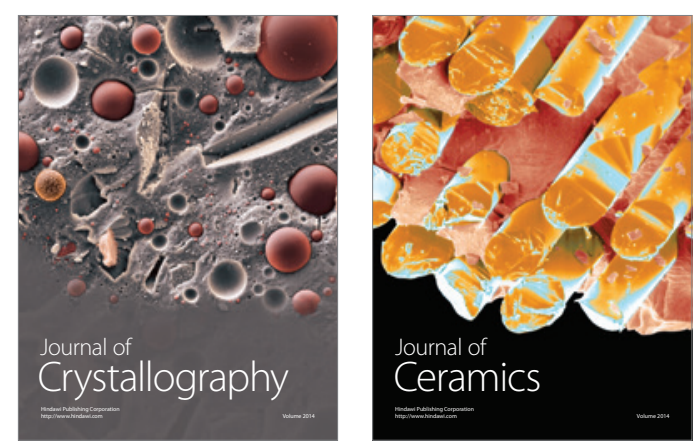
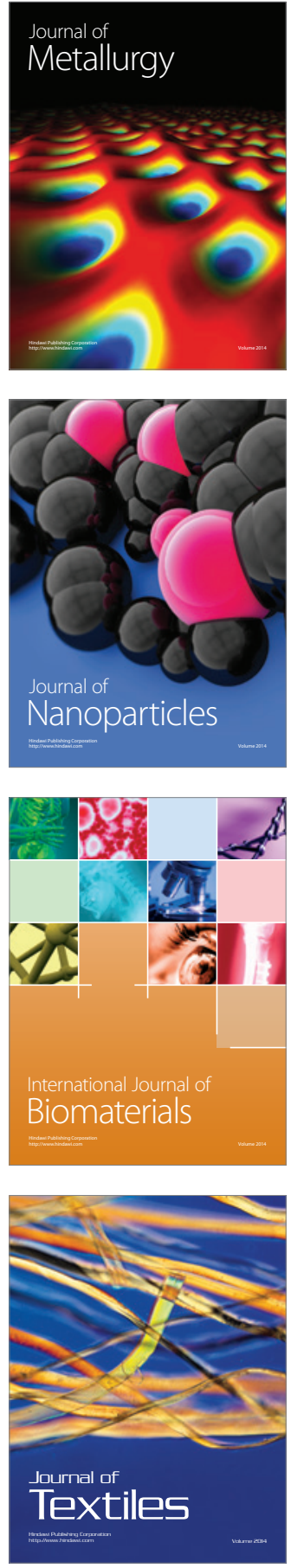